\title{
DEVELOPING DIVERSITY THROUGH SPECIALISATION IN SECONDARY EDUCATION: COMPARING APPROACHES IN NEW ZEALAND AND ENGLAND
}

\section{Jeremy Higham, Paul Sharp and Mark Priestley}

\author{
School of Education, University of Leeds
}

Correspondence to: Jeremy Higham, School of Education, University of Leeds, Leeds, LS2 9JT.

J.J.S.Higham@education.leeds.ac.uk 


\begin{abstract}
The paper compares approaches to curriculum specialisation in secondary education in New Zealand and England. In both countries there have been movements towards increased specialisation, though these have been quite different in form and scope. In both countries specialisation cannot be divorced from broader education policies designed to increase devolution and choice and the paper discusses these contexts before analysing the different approaches to specialisation and attempting an explanation. The authors of the paper draw on findings from research undertaken in New Zealand schools.

The paper identifies three dimensions that have played a part in influencing curriculum specialisation in both countries. These are opportunity, source of impetus and support. It is argued that while local initiative is possible in New Zealand, central planning and guidance is inadequate. In England while central planning is strong and support is available, it is far from clear that real specialisation is encouraged by existing curriculum and assessment frameworks. In these circumstances in both countries it seems likely that vertical, rather than horizontal, diversity will continue to hold sway.
\end{abstract}




\section{INTRODUCTION}

The purpose of this paper is to investigate and compare approaches to specialisation in secondary education in New Zealand and England. In both countries there have been movements towards a market-based system of education together with increased specialisation among secondary schools, although as we shall show this has been quite different in form and especially in scope. Although it would be possible to compare the development of specialist schools in many countries across the world, where a general increased parental demand for such provision is encouraging their establishment and expansion, New Zealand and England would seem to be particularly pertinent choices for comparison as their education systems have many similarities and yet provide contrasting patterns of specialisation. Now economically more dependent on Asia than on Britain (as in the colonial past), there is evidence that in the field of education, New Zealand continues to be influenced by English education policy. What is therefore of interest to examine is the extent to which the different education systems, the level of government encouragement and support and the differences in underlying philosophy affect the form and development of approaches to specialisation. 
Within current education policies in New Zealand and England specialisation cannot be divorced from broader policies designed to increase devolution and choice within secondary education and the education system more generally. Both countries have been in the forefront of what Whitty, Power and Halpin (1998) identified as a widespread if not global phenomena, involving the delegation of some powers and responsibilities to individual schools, while arrogating others to the centre, coupled with increased parental choice of school, which linked enrolment closely to school funding. New Zealand has been described as having 'the state-of-the-art quasi-market schooling system in the English-speaking world' (Gordon, 1996). Hirsch has argued that school autonomy and the stripping out of intermediate layers of control and administration between the schools and the central state have gone so far in that country that it has become almost oxymoronic to talk of a national system of education (quoted in Whitty, Power and Halpin, 1998). The English reforms of the 1980s and 1990s which introduced grant maintained schools, local management of schools and open enrolment were warmly endorsed by Chubb and Moe (1992) as the way forward for American and by implication other education systems. In some respects the English and New Zealand reforms were closely linked because there was evidence of policy borrowing between the two countries. Smyth claims that New Zealand's policy blueprint Tomorrow's Schools (Department of Education, 1988), which followed the Picot Report (Picot, 1998) and ushered in many of the changes, was 'hijacked directly from Thatcher's England' (Smyth, 1993). This policy-borrowing had the potential to operate in both directions as shown by the way in which the English Grant Maintained Schools Foundation was reported as considering recommending the introduction of a system based on the New Zealand bulk-funding model under which schools could opt out of local authority control without the need for a parental ballot (Catherall, 1995). There are differences in education policy between the two countries. For example, the New Zealand Curriculum Framework is far less detailed and prescriptive than the English National Curriculum, even in its post-Dearing slimmed down version, while there is no English version within 
compulsory education of the New Zealand unit standards. Also as we shall show within New Zealand policy there were fragments of more collectivist or compensatory approaches to educational provision almost entirely absent from English education policy, certainly under the previous Conservative government.

However, despite these differences between English and New Zealand approaches to education policy from the late 1980s the similarities remain strong enough to make a comparison of the different approaches to specialisation both worthwhile and instructive. The rest of this paper is devoted to a delineation of those approaches, an analysis of the differences and a tentative attempt to explain them. Thus the following two sections will describe and analyse specialisation in secondary education in England and New Zealand, while the final section will draw the analysis together and suggest some explanations for the differences. Our descriptions of specialisation in the two countries are rather different. Specialisation in England is largely described at the policy level with particular emphasis on the specialist schools programme which has been the keystone of both the Conservative and Labour governments in this area (research is currently being conducted in the School of Education, University of Leeds on the implementation of this programme in schools and subsequent papers will include empirical analysis at school level). In New Zealand, as we shall show, there has been no comparable government initiative to promote specialist schools and therefore where specialisms have been developed they have been largely the result of local initiative and efforts. Section three of the paper therefore consists principally of description and analysis of school level attempts to develop specialisation derived from our recent research in New Zealand schools.

Before proceeding to discuss approaches to specialisation in the two countries however, we shall briefly consider the theoretical role of specialisation within quasieducation markets. For market advocates there are at least two conditions which must be met before the education market can operate efficiently. The first of these is the 
provision of information to parents (consumers) about the choices on offer so that they can make rational choices. Thus in England information on schools in the form of league tables of test, examination and attendance records, OFSTED reports and statutory information which all schools must publish in their prospectuses is now available to parents, while in addition many schools have stepped up their own efforts to inform and attract potential parents. In New Zealand there is no statutory requirement for schools to publish specific information in this manner, although many schools are similarly enthusiastic about marketing themselves. The New Zealand Qualifications Authority (NZQA) publishes statistical information on examinations results in a non-league table format; this information contains so-called benchmarks which enable schools and parents to judge the performance of a particular institution against averages collated from similar schools. The Education Review Office (ERO) publishes reports on school performance; these are available to parents seeking to make informed choices about schools. The second condition for the effective operation of the market is the provision of a diversity of different types of school, since one of the criticisms of the previous comprehensive approach to secondary education was that it produced a dull uniformity which failed to reflect the different abilities, aptitudes and aspirations of potential pupils and their parents. On this view a choice between essentially identical offerings would be no choice at all. Thus any local education market should ideally provide a range of different types of school from which parents can choose. These schools might vary by: governance e.g. grantmaintained, voluntary aided, City Technology Colleges and LEA controlled schools; size; admission criteria e.g. single sex or co-educational, selective or non-selective; curriculum e.g. general or specialised. It is the latter diversifying characteristic which is of central importance in this paper and again ideally within any local market advocates would wish to see a range of schools emphasising different curricular specialisms or none. In this way some sort of market equilibrium could be established within any given area so that most parents would be getting schools of their choice and the undesirable situation whereby popular schools choose pupils could be 
avoided. The aim would be to produce a horizontally diversified range of different but equal schools. Quite clearly this idealist scenario raises several questions. First, did the previous approach produce the 'dull uniformity' claimed? Second, within the confines of national curricula is diversity possible - this raises oft-explored tensions between neo-liberal and neo-conservative approaches? Third, can local education markets, especially in rural areas, sustain the differentiated provision which the market model assumes? Fourth, even where a range of provision can be achieved can it avoid vertical diversity, that is the establishment of a hierarchy of schools within a local market? It seems fairly clear to us that a pure, horizontally differentiated market is likely to exist in few, if any, localities. Probably most market advocates would accept this proposition but would still argue that even in an impure form it would still represent an improvement on other approaches, and particularly what they style the bureaucratic, mass education model with which they usually compare their preferred approach. Quasi-market theory also indicates that specialist schools would be established in response to real or perceived demands from consumers (parents) in much the same way, for example, as a new retail outlet. Where funds are fully devolved to schools there should be no necessity for the central state to play a role because schools will be responsive to their local communities and will deploy their resources to establish specialisms where they are convinced that it will be in their interests to do so by establishing a particular niche market for themselves.

So much then for the theory of specialisation within a quasi-market setting. In the sections which follow we set out the rather different ways in which degrees of specialisation in secondary education are being pursued in England and New Zealand.

\section{SPECIALIST SCHOOLS IN ENGLAND}


There is a sense, of course, in which specialisation in secondary education is nothing new. Taking the post-World War II period alone, the tripartite system created different types of schools, with different curricula, for allegedly different kinds of pupils. It should be noted though that the curriculum provided in grammar schools varied little from one to another, although it was clearly more academic in nature, for example including classical and modern languages, than that found in secondary modern schools.

After widespread comprehensivisation, the absence of curricular prescription continued and, as the concept of a comprehensive school was embraced, many secondary schools were able to maintain or develop curricular orientations perhaps through responding to particular features of their local environment or through the interests and enthusiasm of individual headteachers or staff. As we shall see in the following section both these factors remain important in explaining the extent and degree of specialisation in New Zealand schools. Following the progressive introduction of the National Curriculum, it is uncertain how many English secondary schools have been able to maintain or establish this sort of homespun, 'organic' approach to specialisation.

In England however, the last decade or so has seen the development of a much more centralised, state-driven approach to specialisation and it is this which we focus upon in the remainder of this section with particular emphasis upon the specialist schools programme which was introduced in 1994.

The thrust towards specialist schools was first mooted by the Conservative governments of Margaret Thatcher and John Major during the 1980s and early 1990s. The first examples of this variant of school were the City Technology Colleges (CTCs). These controversial institutions were intended to be funded, at least in part, by private sponsorship from industry. They focused on the use of technology across 
the curriculum, and sought to attract students who had an aptitude for technological subjects. These were to be a 'new kind of school orientated explicitly towards an enterprise culture driven forward by high technology' (Edwards and Whitty, 1997). It was clearly hoped that they would help to ensure the future prosperity of Britain as a trading and manufacturing nation, although in the event only fifteen were ever established. The 1991 Technology Schools Initiative (TSI) further extended government support for this type of curriculum, by giving one-off capital grants to secondary schools who were willing to specialise in the direction of technology. By far the most extensive initiative to establish specialist schools has been the specialist schools programme. This was first signposted in the 1992 White Paper Choice and Diversity: A new framework for schools (DfE, 1992) which extolled the virtues of diversity and proposed the establishment of a network of Technology Colleges, specialising in Technology, Science and Mathematics, to build upon the achievements of the CTC and TSI programmes. The first Technology Colleges were announced in February 1994 and in November of the same year the network was extended in the specialist schools programme to include Language Colleges. The original Technology Colleges programme was open only to grant maintained and voluntary aided schools in a fairly naked attempt by the Conservative government to persuade more schools to opt out of LEA control. In November 1994 this requirement was dropped and the programme was opened to all state secondary schools. The specialist schools programme was expanded further in Summer 1996 to include Sports and Arts Colleges. By September 1999 there will be 365 specialist schools in the programme and the government aims to establish 500 by 2001 at a total cost of $£ 65 \mathrm{~m}$. Despite the various changes outlined above, in many respects the basic aspects of the programme have remained largely unchanged. Existing schools apply to the DfEE for specialist status for three years in the first instance, with the possibility of redesignation for a further three years (already achieved by several schools). They must raise $£ 100,000$ in cash or kind for capital projects from business sponsors and produce a three year development plan showing how they will meet the broad aims of the programme and 
the detailed objectives which they have set themselves. Once accepted a school receives matched $£ 100,000$ capital funding and up to a maximum of $£ 100,000$ per annum recurrent funding on a per capita basis from the DfEE. Thus over a three year period a school stands to gain up to $£ 500,000$ in additional funding (including sponsorship) with more to come upon successful redesignation. Although the programme was initiated by the Conservative government the Labour government has proved an enthusiastic supporter and its White Paper Excellence in Schools placed the specialist schools programme at the centre of its strategy for 'modernising the comprehensive principle’ (DfEE, 1997). Labour has however, introduced one major change to the programme. From July 1997 applicant schools have been required demonstrate a 'community focus' and draw up targets for links with other schools and the local community showing how they will share their expertise with others.

Comparison of the ways in which specialist schools might theoretically be developed in a quasi-market with the ways in which they have actually been developed under the specialist schools programme invites several comments. It is clearly apparent that insofar as specialist schools in England can be identified with the specialist schools programme (and we suggest they can be closely identified) they are not a marketdriven phenomena. They have not come about through schools spotting a niche in their local education market and applying their own resources to its exploitation. The programme is clearly powerfully state-driven both in its conception and operation. At the policy level it is based upon a human capital/modernisation diagnosis of the requirements of national competitiveness in the modern, globalising world, hence the strong focus upon technology and languages. Clearly meeting the educational challenges posed by international competition could not be entrusted to the education quasi-market and the supposed wishes of parents and school responses to those wishes, but required governmental intervention. In their practice specialist schools are closely supervised by the DfEE's specialist school's unit. They are required to submit annual reports and the third year of recurrent funding is dependent upon them 
satisfying the DfEE that they are carrying out the agreed development plan. Development plans themselves have been required to become steadily more specific and to have greater emphasis on targets related to outcomes, mainly expressed through examination results in the specialist areas. Thus the specialist schools programme is a tightly managed and supervised programme, although there is some latitude for schools to develop their own targets and performance indicators. Another feature of the specialist schools programme is that it has not been compensatory, that is to say it has not generally been used by government as a means to support struggling schools. Rather it was made clear in the guidance provided to potential applicants that in order to be successful it is likely that they must already be succeeding, or at least improving, by some of the commonly accepted indicators. The guidance states:

Where current examination performance is modest there must be evidence of improvements over the recent past. Technology Colleges will be expected to demonstrate improved standards by meeting challenging but realistic targets. Consequently it is unlikely that a school whose examination results are on a declining trend will be successful in its application unless there are good reasons to explain the trend and the application is part of a convincing strategy for improvement. (original emphasis) (DfEE, 1998)

The Labour government has introduced some changes in the orientation of the programme by indicating that 'Some preference will be given to applications from schools in areas of social deprivation' and that 'An application from a school within an Education Action Zone (EAZ) will have preference over other applications provided the EAZ school application meets all other requirement' (DfEE, 1998). It is still too early to say what the effects of this encouragement to schools in disadvantaged areas to apply will be. Prior to these changes the guidance was interpreted by schools as meaning that they must have a track record in the specialism for which they are 
applying if they wish to be successful. Thus it may be that the programme has so far accentuated diversity which already exists rather than encouraging schools which have offered a 'standard' curriculum to diversify. In addition however, it remains uncertain how different the curricula of the specialist schools are compared to those found in schools outside the programme. One hypothesis would be that the specialist schools are doing mainly what other schools do, but doing it better, or at least with greater resources. Research currently being undertaken for the DfEE by the School of Education, University of Leeds and the Centre for Educational Research, London School of Economics will throw light on these questions. The programme has also come under attack from some commentators as an assault on comprehensive schooling. This is because specialist schools have the option of selecting up to $10 \%$ of their incoming pupils on the basis of aptitude in the specialist subjects. Early indications are that relatively few specialist schools have taken up this option, mostly because they oppose selection on principle, but also because of the difficulties of selection by aptitude at 11 years of age, particularly in technology. However, despite the rejection of overt selection by many schools it is possible that self-selection is taking place and that the specialist schools are attracting greater numbers of pupils from relatively advantaged home backgrounds. This has led some commentators to suggest that specialist schools are likely to become elevated above 'ordinary' schools in local hierarchies. As yet however there is little or no evidence of the effects of specialisation on admission patterns to specialist or neighbouring schools.

\section{SPECIALIST SCHOOLS IN NEW ZEALAND}

\section{State-sponsored specialisation}

The situation with regard to government funding of specialist programmes in New Zealand has been substantially more limited than in England. There have been no 
programmes comparable to the CTC, TSI and specialist schools initiatives. Our research has indicated that the Ministry of Education does not really consider specialisation to be an issue; for instance enquiries made to the Ministry have highlighted the fact that there is little or nothing along the lines of a coherent policy to pursue specialisation at government level. However, there have been some examples of Ministry expenditure that while not aimed at encouraging schools to specialise have had an impact on the curriculum in schools; in some cases such funding has led to institutions developing specialist programmes. The first part of this section thus looks at the comparatively limited state-sponsored attempts to promote specialisation.

Such attempts have taken four main forms. First is the provision of capital grants to build facilities; a notable example is a high school on the West Coast of the South Island, which received a capital works grant in the region of $£ 300,000$ to build a Technology Centre in 1997. However, while these sorts of grants inevitably make it easier for schools to provide excellence in the curriculum area in question, it is less certain that they transform them into specialist schools. Grants of this nature are usually intended to allow schools to upgrade or replace old facilities; schools get allocated money according to their place in the queue on the capital works list.

A second 'pot of money' made available to schools by the Ministry of Education is the Secondary Tertiary Alignment Resource (STAR). By enabling schools to run courses that would only normally be available in tertiary institutions, such as electronics or catering, STAR opens up a range of specialist programmes to school students. Schools have been eager to tap into the funding, and this has enabled programmes to be run that would otherwise have been impossible. However, the limited nature of STAR ( $£ 7.9 m$ to be allocated nationally for 1998) makes it unlikely that the fund will lead to the establishment of specialist schools. It merely allows particular schools to run subject options that could not be otherwise funded. 
A third type of Ministry funding has involved financing a range of specific curriculum projects, often small in scale and involving sometimes only one or two schools. A notable example of this trend has been the Computers in the Classroom initiative which was set up to operate in a single school (Boyd, 1997). In at least one case there has been a stated aim from the Ministry that the funding would lead to the establishment of specialist schools, although this has to be seen as an isolated, even idiosyncratic development, particularly when viewed against the wider framework of Ministry-led curriculum projects. This initiative, the Technology Development Schools Project, was launched by the then Minister of Education, Lockwood Smith, via an announcement in the Education Gazette in 1993. The imperatives driving the initiative are not clear, but seem to include the following: awareness of the existence of technology schools in other countries, especially in America, and an understanding of the potential of such schools in New Zealand; the imminent development of the Technology curriculum within the Curriculum Framework; and growing concern at the low numbers of experts within New Zealand in the fields of science and technology (Hawk, 1997). The initial announcement called for bids from schools who wished to become 'lighthouse' technology schools; subsequent to this announcement, four high schools were designated as such, and received funding between 1994 and 1996 for this purpose. Each of the schools was granted a sum of $£ 133,000$ in order that they could offer curriculum experiences in all of the technology areas, provide professional development for staff and implement twilight community education programmes. The schools spent the money in different ways; for example three schools chose to focus on developing their school libraries into high technology information centres, and the fourth invested in portable computers, primarily for staff use.

The project has finished now, and is largely remembered as being less than successful (Hawk, 1997). The money granted has been seen as inadequate for the stated aims of setting up technology schools, and the schools in question did not have the resources 
to continue with the project after the funding ceased, especially as the hoped-for sponsorship from industry did not materialise. The government commissioned evaluation of the project was especially critical on this score, stating that,

'it is significant that the four schools selected serve comparatively low socio-economic communities for their geographical areas. It became clear by early 1995 that the money that the schools received through the grant was adequate to provide them with the level of hardware and software that most other schools have, but which these schools would not otherwise have afforded. It was certainly not enough to make them into the kind of specialist schools that the original Gazette announcement signalled when it specified that the schools would attract 'students who would probably not otherwise enrol at the school concerned ... and who may be attracted to the opportunities offered by a technology development school' ' (Hawk, 1997).

The unclear nature of the Technology Development Schools Project objectives was without a doubt a reason for its failure. Again the official evaluation was scathing in its criticisms, emphasising that the,

'project incorporated and hinted at a number of goals, but did not clearly state what the key underpinning objectives were. This seemed to result in a diverse set of requirements that eventually became unrealistic' (Hawk, 1997).

Furthermore, the very fact that schools were only given five weeks (falling over a holiday period) to produce a detailed proposal, militated against comprehensive planning by the schools in question. In summary, it would seem that this well- 
publicised project was beset from the very outset by poor planning, unclear and unrealistic expectations and inadequate funding.

Interestingly then both this project and the provision of capital grants referred to above had clear compensatory elements in providing funding for schools which had old facilities and/or served 'comparatively low socio-economic communities'. This is in marked contrast to the English approach where, until recent encouragement to schools located in Education Action Zones to apply for specialist status, factors such as age of buildings and facilities and socio-economic factors were not taken into account when admitting schools to the specialist schools programme.

A more recent curriculum project supported by the Ministry is the SLLP (Second Language Learning Programme). This 'exploratory study' has allocated $£ 1.6 \mathrm{~m}$ for 'second language learning for students in Years 7 to 10' (Ministry of Education, 1997). New Zealand has very little tradition of second language learning in comparison to other developed countries. The aims of the SLLP have been to boost the numbers of students learning a second language, and to lower the age at which instruction commences, by getting programmes into primary and intermediate schools at Years Seven and Eight. The project has involved over one hundred schools grouped into clusters. These clusters normally consisted of several primary or intermediate schools and one high school; it has usually been intended that the primary schools would utilise the skills of specialist language teachers in the secondary schools to deliver a programme of foreign language teaching to students in Years Seven and Eight. This project thus has echoes of the ways in which the specialist schools programme in England has been reoriented by Labour to include a 'community dimension'. The schools concerned have spent the allocated funds on a variety of resources, usually staffing, but also computers and books and other equipment. SLLP has run for two and a half years, finishing mid-way through the 1998 academic year, and it is difficult to see how many schools will be able to continue with the 
programmes run under the auspices of the project, now that funding has finished, let alone establish themselves as specialist language teaching schools.

A fourth manifestation of specialisation has been the establishment of Kura Kaupapa Maori (schools with a Maori charter) which are intended to provide a holistic Maori spiritual, cultural and educational environment. At the time of writing there are 59 Kura although only five have secondary education programmes. We refer to the Kura only briefly in this paper because they are mainly confined to primary education and because space restrictions mean we cannot do justice here to the complexity of the relationship between Maori education and specialisation. However, it is important to note that the government is now putting funding into Maori education including the Kura. Whitty et al. (1998) comment:

'This alternative choice within New Zealand education, however, is not expressed in quasi-market terms. Instead, and this may be significant for analyses of alternative ways of managing local education systems, the Kura have been developed in response to a need felt and expressed by a minority constituency within New Zealand society dissatisfied with mainstream educational provision. It stresses collective rather than just individual needs.' (Whitty, Power and Halpin, 1998)

This more collectivist approach with systematic state funding has no counterpart in the English approach to specialisation.

It is apparent that there has been no large-scale funding of specialist schools, or of specialist programmes in New Zealand, as has been the case in England. Moreover there is little evidence of sustained and long-term government policy making in this area. Consequently, relatively few schools have chosen to set up such programmes. It is probably fair to say that the Ministry of Education sees its role primarily in terms of 
co-ordinating the production and implementation of curriculum prescriptions, rather than in providing the impetus for curriculum projects that meet local needs; whilst the Ministry has been generally supportive of initiatives such as the Sports Academy described in the third section of the paper, such support has been reactive and rhetorical rather than comprising concrete assistance such as funding. Such inaction lends credence to allegations that the government is wedded to an ideological commitment to devolve responsibility for curriculum development to schools. Critics of the government are quick to assert that 'the Ministry is no longer an arm of the state which offers educational/pedagogical guidance or leadership' and that allegedly this has occurred as a result of the state seeing itself as 'an unnecessary interposition between consumers (students and parents) and providers (teachers)' (O'Neill, 1996/1997). This is in marked contrast to the situation in the UK where, as has been indicated above, the CTC, TSI and specialist schools programme could all be seen as 'a direct intervention in the market, an 'interference' in the interplay in supply and demand' (Edwards and Whitty, 1997). In the next section we turn to some of the examples of the local initiatives through which such specialisation as has been achieved in New Zealand has come about.

\section{Specialisation through local initiatives: The national context}

Before we go on to describe and analyse some of these local initiatives it is important to set them in the context of national policy development, in order to evaluate to what extent the conditions under which schools are able to attempt to specialise under their own steam meet the theoretical conditions of the quasi-market described in the introduction to the paper. Educational milestones such as Tomorrow's Schools (Department of Education, 1988) have had an impact on curriculum development in some schools. The virtual disappearance of zoning (catchment areas), and the devolving of responsibilities for financial and administrative management have led to 
the establishment of competitive markets in areas where the concentration of schools is sufficiently high to allow market choice. In turn this has been partly responsible for the development of some degree of horizontal diversity in the form of curriculum specialisation, as well as encouraging the development of the vertical diversity alluded to in the introduction to the paper. Similarly, the development of the Curriculum Framework since 1993 and the subsequent implementation of unit standards have influenced curriculum policy in schools which have sought to set up specialist programmes. The Curriculum Framework is commonly perceived as squeezing the time available to subjects that are not part of the standard fare; fears have been expressed that non-essential areas may disappear from many timetables, and that the 'frills' may be squeezed out by an overemphasis on the 'basics' (Snook, 1990). However, despite the pressures of curriculum prescription, on balance it is probable that the Picot reforms and the introduction of unit standards have created favourable conditions for the implementation by schools of specialist programmes to meet local needs. For example, our research has indicated that many of the schools surveyed see unit standards as offering an alternative to the traditional school curriculum thus opening up opportunities for accreditation in vocational and other areas that have not been hitherto available to schools. In a similar vein, the Picot reforms are seen by some schools as providing them with the financial and administrative autonomy that is necessary to initiate the sorts of programmes that are the focus of this paper. Even the perceived constraints of the Curriculum Framework are not necessarily as great as believed; O'Rourke, the Secretary for Education in 1995 wrote:

'New Zealand Curriculum Framework . . . (does) not stipulate how much time should be spent on any one essential learning area. It is up to the boards of trustees, the principal and staff to determine what a balanced curriculum should be for their school.' (O'Rourke, 1995). 
Most of the schools surveyed pointed to the favourable climate of the 1990s as a factor that has enabled them to achieve what would not have been possible before the reforms. In some respects then the conditions for specialisation in New Zealand seem rather more propitious than in England where the national curriculum can be seen as something of a strait jacket, especially at Key Stage 3, and the accreditation system offers less flexibility than that available through unit standards in New Zealand.

\section{Local innovation in practice}

Within this climate, some schools have set up specialist programmes in a variety of curriculum areas. The research that underpins this part of the paper was undertaken to establish the nature of such programmes, and especially to seek to understand why schools have sought to specialise. The research took the form of case study visits with a series of interviews conducted with key staff, including principals, at twelve schools around New Zealand. It must be emphasised that this list of schools is neither representative nor exhaustive; there are undoubtedly schools in other areas of New Zealand that could be considered to be offering specialist programmes. However, our findings provide an indication of the type and scale of specialisation which is being attempted by some New Zealand schools.

Of the schools three were developing specialisms in technology (including ICT), two in art, two in music, two in sport, two in agriculture and one in languages, thus indicating a fairly broad approach to specialisation across the schools.

However, it was apparent that some of the schools investigated could be counted as specialised in only a very limited sense. Although in at least one case the school had built new accommodation specifically to cater for the curriculum area in question what had essentially occurred was a strengthening and improvement of existing 
departments but not a significant specialised reorientation of the curriculum. It is clear, for example, that the Art departments surveyed, while commonly cited as being amongst the best in New Zealand, and as flagship departments for their schools, are difficult to class as specialist; they do not generally receive extra attention from school management in terms of funding, nor are they perceived within the school and in the community as being specialist programmes, worthy of extra attention in the school prospectus. The agriculture programmes surveyed are also dubious claimants to the title 'specialist'. Agriculture formerly enjoyed a higher status within the schools than at present, and that although these programmes are providing specialist teaching, they are now struggling to maintain their share of resources. However, it is clear that most the curricular initiatives researched are examples of innovative programmes that can be described in many respects as being 'specialist'. They enjoy high profiles within their institutions; in several cases even becoming the major focus for the school. Some of the programmes attract enhanced levels of funding, and employ extra specialist staff. In at least two cases, the specialist programmes involve students attaining a level of skills that far exceeds what would be normally expected of students in secondary schools.

\section{Why specialise?}

In the final part of this section we turn to what is a crucial question in the context of this paper. It is clear from the analysis of government involvement in specialist curriculum programmes that funding and support from the Ministry of Education is both limited and does not lead on its own to the development of such programmes. Such funding and support, has often acted as a catalyst to kick-start innovation, but such innovation has also required the existence of other factors and would probably have happened anyway. The research highlighted several reasons why schools have chosen to specialise. These are diverse, and many are unique to individual 
institutions. However it is possible to identify various factors that are common to a range of schools surveyed.

\section{Personnel-driven innovation}

A major factor that seems to be common to all of the schools is the existence of innovative and visionary staff. Sometimes these key personnel are at the level of senior management. One area school for example had made a major investment in ICT developing impressive networked facilities including Internet access and encouraging use across the curriculum. This school, which serves a rural catchment area, also uses networked computers and audiographic conferencing to deliver school subjects that only attract small numbers of students in twelve small rural schools. It has enabled students at these schools to take subjects such as Japanese and Classics in the absence of specialist teachers in their own schools by utilising on-line teaching. The visionary and innovative principal of the school was the main reason why the school has 'stepped out of the education comfort zone, and taken a risk' (Zwimpher, in Cantatech, 1997). She has been largely responsible for producing the ideas, for enthusing staff, the Board of Trustees and the community with her vision, for providing the drive necessary to implement the programmes, for obtaining up to fifty cheap and donated used computers from businesses, for raising funds, and for appointing staff, including the new deputy principal, who share her interest and vision.

However, while there are other examples of innovation being led by the principal, more generally the innovation and the impetus are found, at least in the first instance, at the level of head of department. This is certainly true of the two schools emphasising specialist Music programmes and the development of a Technology Centre at another school. The initial plans for this were submitted in 1995 as part of a bid for Ministry funding; when this bid failed, the head of department, in his own words 'driven' to achieve his goals, decided to go ahead anyway with the building 
project, and has subsequently invested most of his free time, at a significant personal cost, to realising what has become his dream. The result is a Technology Centre, that while not completed, is the envy of many local schools, and which, in providing a high quality technology education for its pupils, has attracted praise from many quarters. This is certainly a specialist programme; the school is acknowledged as a leader in the field, and technology provides a focus for many of the activities that take place in the school. The development is due in part to a number of other factors. These include the traditional blue collar nature of the school's environment. Another major factor is the development of the national curriculum statement in Technology, which has been acknowledged by the head of department as essential to the realisation of his goals:

'if it wasn't for the technology curriculum, we would never have got the go ahead for something like this' (Interview with head of department, 1998).

Both of these factors have ensured that the senior management and Board of Trustees have remained sympathetic and supportive towards the notion of the Technology Centre. However the major factor is the existence of the innovative member of staff, and without his drive and enthusiasm for the project it would not have occurred.

\section{Innovation as a response to specific needs and challenges}

A second factor behind the existence of specialist programmes is the need to tackle specific problems, such as those presented by falling rolls and poor rates of achievement. This represents the closest approximation in practice to the theoretical operation of the quasi-market in education. This has certainly been a factor behind the development of a technology programme at one school which was struggling to retain students past Year Nine, and where student achievement, as measured through external examination results, was poor. A second school which established a Sports 
Academy was largely driven by similar considerations. This concept, originating with a Maori member of staff who wished to raise school achievement within his own community, has been driven forward by an energetic principal. He has described the Sports Academy as being 'entirely student needs-based,' adding that, 'the school's about having the kids stay on at school, getting some qualifications, getting some skills, learning how to fit into the world, and the Sports Academy is just the hook'. The challenge of falling rolls has also certainly been the major impetus behind a third school's involvement in the Second Language Learning Programme. This school faced falling rolls, and in order to deal with the problem of being 'squeezed . . . by (the neighbouring) schools' (former associate principal), the school sought to take advantage of the availability of Ministry of Education funding, and applied to join the project. According to the acting head of department such involvement was seen at senior management level as primarily a 'means of marketing the school', and subsequently gaining a wider profile within the community; it was greatly facilitated by the head of department at the time, who was widely perceived as being 'very innovative' (former associate principal). It must be emphasised that this school can by no stretch of the imagination be described as a specialist languages school. There are no such language schools in New Zealand. However the teaching of languages is much more conspicuous than previously within the school. The links made with feeder primary schools have boosted the uptake of languages amongst new entrants to the school in Year Nine, and furthermore raised the profile of the school within the community, potentially affecting enrolment. It remains to be seen whether the school has the financial means to continue with the programme, now that the Ministry of Education has 'pulled the plug' (former associate principal).

\section{Innovation driven by local factors}

A third major cause of innovation lies in schools responding to the needs of the local environment. This is true of the two schools which had developed Music programmes, which have thrived in the prosperous communities that the schools 
serve. In both cases, these successful schools have responded to a perceived demand for specialist music provision from within the community. In both cases the schools are producing high calibre musicians who are succeeding competitively at the highest levels. This has invariably provided much needed prestige for the schools in question, and it is clear to see that in these cases, the development of specialist programmes conforms with quasi-market theory; specialisation has clearly occurred in response to market demand, and has led to the schools establishing a particular niche market which further raises the profile of the school in the community. As previously mentioned, one of the factors behind the development of a specialist technology programme at another school was a need to respond to the socio-economic profile of the surrounding area; the traditional blue collar nature of the local employment market has made an emphasis on Technology a good selling point for the school. Similarly, another of the schools emphasising technology has responded to local needs by seeking to retain some of the more traditional craft biased facets of Technology for those students who are likely to seek employment locally on leaving full time education. At the same time it has sought to address the needs of more academic students who are likely to leave this rural and isolated community to attend tertiary institutions in bigger centres. According to the principal, the school's major goals were to,

$$
\begin{aligned}
& \text { 'give the kids from the district a leg-up .... (and) to counter, to some } \\
& \text { extent, the cultural shock of going to live in a city when they } \\
& \text { eventually leave for tertiary education' (Interview with school } \\
& \text { principal). }
\end{aligned}
$$

In both these latter cases, Technology is seen as being the key to enhancing the educational opportunities of the school's students, either through manual training, or through the development of the problem-solving skills that are the hallmark of the new technology curriculum. 
The importance of the local geographic environment is manifest in one of the schools which has sought to develop Outdoor Education programmes since the late 1970s. The principal of the school points to two main factors which have been responsible for the direction that the school has taken. Firstly, the town in which it is located in one of the driest and sunniest regions in New Zealand. Secondly, the town is geographically isolated, and surrounded by mountainous countryside. These factors have meant that the school has had two advantages when formulating curriculum policy. The local climate lends itself to activities that take place outside, meaning that the programme of field trips, camps and residentials, that take place throughout the school, are unlikely to be disrupted by adverse weather. The isolation of the town has meant that policy has been traditionally formulated and implemented without interference from central government, and in the absence of competition from other schools. This has led to a very interesting paradox in relation to quasi-market theory, since it is the very absence of competition which has encouraged the school to experiment with alternative approaches to education in a way that a school in a more competitive environment might have been much less likely to do. Ironically, this school was the only one surveyed to claim Tomorrow's Schools actually hindered it in its efforts to pursue its goals. In this case, the school has always enjoyed the autonomy that Picot has brought to school administration; any benefits that have accrued from the report have been more than offset by the disappearance of earmarked grants that formerly facilitated the Education Outside The Classroom and the Outdoor Education programmes. As with all of the schools surveyed, the programme has also been driven forward by innovative and interested staff.

\section{Traditional specialisms}

A final cause of specialisation that our research identified lies in the area of tradition and this recalls our earlier suggestion that specialisation should not be seen as being necessarily new. In New Zealand this is particularly true of the long-standing 
Agriculture programmes at two schools both of which have traditionally educated the children of farmers. It is therefore not surprising that both schools have developed specialist courses in agriculture and horticulture and both possess farms. However in both cases the programmes are substantially reduced from their halcyon days, and are now under threat from budget cuts and competition for timetable space from other subjects designated as Essential Learning Areas by the Curriculum Framework. Thus while these schools have maintained an element of specialisation both are feeling pressure to move towards a more homogeneous 'standard' curriculum. This reflects the way in which Agriculture as a school subject has been affected nationally by a decline in the importance of farming, and at the schools in question by the changing socio-economic profiles of the students with fewer coming from farming families than in the past.

\section{CONCLUSION}

It is clear that post-primary education in New Zealand exhibits many parallels with its counterpart in England. In general, both countries have experienced a governmentdriven thrust towards marketisation, and this has been accompanied by a drive towards curriculum specialisation in many schools. However, our research has indicated that there exist many substantive differences between the unfolding situations in the two countries. In particular one can point to the much greater scale and scope of specialisation in England, and to the substantial differences in the philosophies underpinning these moves. In England there has been a high degree of government intervention in the process of establishing specialist programmes, in stark contradiction to the free-market philosophies espoused frequently by successive governments; this top-down approach has led to many schools seeking specialist status. In New Zealand, adherence by the National governments of the last decade to prevailing neo-liberal orthodoxies has precluded the sorts of large-scale government 
interventions that might facilitate the setting up of substantial numbers of specialist schools; such programmes as have become established have largely remained local affairs, driven by local factors. In seeking to understand the imperatives that have driven curriculum specialisation in secondary schools in both countries, we have identified three main common dimensions or factors that have played a part in influencing such development in both countries. These are opportunity, source of impetus and support.

Opportunity is an important prerequisite to the setting up of specialist school programmes. The lack of central prescription traditionally inherent in the curricula of the two countries provided opportunities for schools to diversify in this fashion. This situation has changed markedly since the 1980s, as two opposing, but interwoven trends have developed. First, the development of the quasi-market in education, prompted by neo-liberal philosophy, has provided schools with the administrative and financial autonomy to diversify away from the norm. Many of the New Zealand schools surveyed by us have, as previously described, referred to the post-Picot climate as being instrumental in enabling them to establish their programmes. Second, and in tension with neo-liberal philosophy, there has been tightening curriculum prescription, as governments have paradoxically attempted to increase central control over what has been taught. This has created conditions under which it would seem that diversification is less likely to occur. The curriculum overcrowding inherent in the application of the English National Curriculum, even in the increasingly slimmed down versions of Key Stage 4, has militated against diversity. Similar fears have been expressed about the New Zealand Curriculum Framework, although this is less prescriptive, and we would point to the findings of our research which demonstrate that the parallel development of unit standards has actually helped schools to diversify. 
Thus it can be seen that the situation with regard to opportunity for specialisation is complex and subject to the interplay of opposing forces, namely administrative climate and curriculum requirements. Analysis of opportunity does not, therefore, suffice to explain why specialisation has occurred in England and New Zealand. Indeed the opportunities for specialisation would seem to be greater in New Zealand than in England both because administrative and financial devolution has gone further and because curricular and assessment frameworks are looser. However, one must look beyond the simple existence of opportunity at the existence of sources of impetus. In England the situation is more clear cut than in New Zealand. The existence of government projects, such as the specialist schools programme, has plainly acted as an impetus to change; the availability of substantial central funding has acted as the 'carrot', ensuring the participation of a large number of schools in the initiatives described. The comparative absence of such central direction and its accompanying funding has proved to be a barrier to specialisation in New Zealand. Where central impetus, and more importantly, funding have existed schools, as in England, have sought to diversify. However as described, such funding has invariably been either short-term or small in scale and scope; consequently it has had little longterm effect on curriculum policy within schools. Instead where specialisation is to be found, one must look to local or other immediate sources of impetus. These include: the need to respond to specific challenges and crises; the needs of the local environment; local demand for a particular type of curriculum provision; and most importantly the drive provided by innovative key personnel. In general the development of specialisation in New Zealand supports Hirsch's (1997) contention that competing schools change their character only to a limited extent in search of niche markets. He argues that:

'This is not perhaps surprising, since most schools put a priority on retaining their sizeable semi-captive home markets - those living 
nearby - who might not happen to like particular changes in character or specialism chosen by a local school.' (Hirsch, 1997)

It is important to acknowledge that as we showed in our detailed analysis in section three of this paper there has been some development of specialisation in New Zealand in at least some cases partly prompted by perceived needs of improving market position. However, the scale and scope of specialisation in New Zealand is not likely to produce the horizontal diversity required for the optimum operation of the quasimarket and in its absence there is evidence for increasing vertical diversity among New Zealand schools (Waslander and Thrupp, 1995).

It is interesting to note parallels between the situation in New Zealand today, and that in Britain before the onset of Thatcherism. As highlighted previously, the specialist schools programme has focused until recently on schools which already had an interest in the area of specialisation, and it is reasonable to assume that these interests were often initially prompted by local factors within the climate of curricular flexibility that existed prior to the National Curriculum. Another point worthy of note is the socio-economic profile of schools involved in specialisation. The specialist schools programme in England has until recently overtly concentrated on already successful schools. In Israel and the United States, the 'socio-economic level of the parents in speciality schools is higher than that of parents in neighbourhood schools' (Goldring, 1997). The admittedly rather scanty evidence so far available tends to suggest that specialised schools in these countries are using their specialisms to emphasise their all-round 'excellence'. This seems likely to accord with the aspirations of many parents who seek 'good' rather than specialised schools for their children. For example, Whitty et al (1993) in their study of CTCs found that parents were as often attracted by the promised academic excellence and traditionalism of the schools as by their technological status. In contrast, our research in New Zealand indicates that specialisation seems to occur more readily in lower decile schools; with 
the exception of the music schools, most of the programmes surveyed were established in schools at least partly in response to problems associated with low socio-economic status.

A third dimension involved in specialisation is support. This is invariably linked to the issue of sustainability. The situation in this respect in England would appear to be secure in at least the medium term, as the majority of specialist schools are associated with ongoing government policy, and therefore available funding. In New Zealand, central funding for curriculum projects has been significantly less sustained. We have already drawn attention to the fears of the language school, where the future of the SLLP initiative is in considerable doubt in a struggling school once the funding dries up. Long-term funding will remain an issue for all schools seeking to specialise within such an environment. Invariably this means that hard decisions have to be made; specialist programmes funded from the standard operating budget mean that money becomes unavailable elsewhere, and as a consequence the pressure will always be on schools to conform to the demands of the Curriculum Framework. Given these considerations, it is hardly surprising that specialisation is considerably less common in New Zealand than it is in England. Whilst the opportunities exist for specialisation to occur, the sources of impetus are not so powerful, and sustainability is hampered by the lack of ongoing financial support. Hirsch (1997) argues that ' . . mechanisms for achieving diversity need to balance some guidance from the centre with the encouragement of genuine local initiative'. He uses an American example to argue that:

' . . . educational dynamism and diversity is more likely to be created by empowering teachers rather than over-defining their jobs. Such empowerment may nevertheless need to be combined with some degree of planning for diversity given the disinclination in most cases 
for schools to seek 'niche markets' for competitive reasons alone.' (Hirsch, 1997)

We suggest that in both New Zealand and England the balance advocated by Hirsch is lacking. In New Zealand while local initiative is possible, central planning and guidance is inadequate. In England while central planning is strong (arguably too strong) and support, at least in the form of funding, is available, it is far from clear that real specialisation is permitted by existing curriculum and assessment frameworks. In these circumstances in both countries it seems likely that vertical, rather than horizontal, diversity will continue to hold sway. 


\section{REFERENCES}

BOYD, S. (1997) Learning by Bytes: Computers in the Classroom (prepared for the Ministry of Education) (Wellington, NZCER).

CANTATECH (1997) Cantatech Handbook (Wellington, Telecom New Zealand).

CATHERALL, S. (1995) Ministers may look to New Zealand model, Times Educational Supplement, 01/09/1995, p. 6.

CHUBB, J. and MOE, T. (1992) A lesson in school reform from Great Britain (Washington DC, Brookings Institution).

DEPARTMENT OF EDUCATION (1988) Tomorrow's Schools: the reform of education administration in New Zealand (Wellington, Department of Education).

DfE (1992) Choice and Diversity: A new framework for schools (London, HMSO).

DfEE (1997) Excellence in Schools (London, DfEE).

DfEE (1998) Technology Colleges Applications: A Guide for Schools (London, DfEE).

EDWARDS, T. and WHITTY, G. (1997) Marketing Quality: traditional and modern versions of educational excellence, in: GLATTER, G., WOODS, P. A. and BAGLEY, C. (Eds.) Choice and Diversity in Schooling: perspectives and prospects (London, Routledge).

GOLDRING, E.R. (1997) Parental Involvement and School Choice: Israel and the United States, in: GLATTER, G., WOODS, P. A. and BAGLEY, C. (Eds.) Choice and Diversity in Schooling: perspectives and prospects (London, Routledge).

GORDON, L. (1996) School Choice and the Quasi-market in New Zealand: 'Tomorrow's Schools' today, in: WALFORD, G. (Ed) School Choice and the Quasi-market (Wallingford, Triangle Journals).

HAWK, K. (1997) Technology Development Schools Evaluation: Final Report (prepared for the Ministry of Education) (Albany, ERDC).

HIRSCH, D (1997) Policies for School Choice: What can Britain learn from abroad?, in: WALFORD, G. (Ed) School Choice and the Quasi-market (Wallingford, Triangle Journals).

MINISTRY OF EDUCATION (1997) Second Language Learning. Curriculum Update 24. (Wellington, Ministry of Education).

O'NEILL, A.M. (1996/1997) Curriculum Reform: Development Issues in Aotearoa New Zealand, in: O'NEILL, A.M. (Ed) Delta: Policy and Practice in Education (Palmerston North: Policy Studies in Education). 
O'ROURKE, M. (1995) in The Education Gazette (Wellington, Learning Media).

PICOT, B. (1988) Administering for Excellence: effective administration in education: report of the Taskforce to Review Educational Administration (Wellington, The Taskforce).

SMYTH, J. (1993) Schools of the Future and the Politics of Blame, PSMI Working Paper 34 (Melbourne: Monash University).

SNOOK, I. (1990) Contesting the Curriculum: the politics of 'basics' and 'frills', in: CODD, J., HARKER, R. and NASH, R. Political Issues in New Zealand Education (Palmerston North, Dunmore Press).

WASLANDER, S. and THRUPP, M. (1995) Choice, Competition and Segregation: An Empirical Analysis of a New Zealand Secondary School Market, 1990-93, Journal of Education Policy, 10(1), pp. 1-26.

WHITTY, G., EDWARDS, T. and GEWIRTZ, S. (1993) Specialisation and Choice in Urban Education (London, Routledge).

WHITTY, G., POWER, S. and HALPIN, D. (1998) Devolution and Choice in Education: The School, the State and the Market (Buckingham, Open University Press). 